\section{SUIMIARY DIABETES SELF-CARE ACTIVITIES (SDSCA) AMONG ELDERLY POPULATION}

KEY WORDS: Elderly, Rural,

Self-care practices, Summary Diabetes Self-Care Activities questionnaire (SDSCA), Type 2 Diabetes.

\section{Dr Harikrishna} B N*

\section{Dr Shruti} Kardalkar

\section{Dr Pravin IM} Pisudde

\section{Venkatesham} Annimalla
MD, Assistant Professor, Department of Community Medicine, ESIC Medical College and Hospital, Hyderabad, Telangana, India. *Corresponding Author

MD, Assistant Professor, Department of Community Medicine, ESIC Medical College and Hospital, Hyderabad,Telangana, India.

MD, Associate Professor, Department of Community Medicine, ESIC Medical College and Hospital, Hyderabad,Telangana, India.

Assistant Professor cum Statistician, Department of Community Medicine, ESIC Medical College and Hospital, Hyderabad,Telangana, India.

Back ground: Diabetes mellitus (DM) is a chronic progressive metabolic disorder, most common non-communicable disease globally. The global prevalence of diabetes among adults over 18 years of age rose from $4.7 \%$ in 1980 to $8.5 \%$ in 2014. In 2016, diabetes was the direct cause of 1.6 million deaths. Objectives: To assess the self-care practices among elderly with type 2 diabetes mellitus and to know the factors influencing it. Methodology: A community based crosssectional study was conducted by selecting elderly through systematic random sampling; socio-demographic details and self-care practices were assessed by Summary Diabetes Self-Care Activities questionnaire (SDSCA).Data were entered in excel, descriptive statistics and chi-square were calculated. Results: 177 elderly diabetics participated in the study. A majority of $49.71 \%$ were in the age group of $69-70 y e a r s .58 .76 \%$ were females, $40.11 \%$ were literates, and $55.93 \%$ resided in joint families. The self-care practices were computed based on Summary Diabetes Self-Care Activities questionnaire (SDSCA) $72.88 \%$ had good and poor self-care practices. Significant factors were $60-69$ years age group, male gender, literates and duration of diabetes (1-5years) $(p<0.05)$.Conclusion: Diabetes and related complications impose a high-burden of catastrophic economic costs by increasing out of pocket expenditure. Self-care in diabetes plays a pivotal role in managing the disease, which has to be practiced more efficiently at individual level with the support from family and community so as to promote healthy ageing amid co-morbidities.

\section{INTRODUCTION}

Diabetes is on the upsurge, no longer a disease of predominantly wealthy nations; the prevalence of diabetes is steadily increasing everywhere, most markedly in the middle-income countries globally. In an effort to address this growing health challenge, since early this decade world leaders have committed to reduce the burden of diabetes as one of four priority non-communicable diseases (NCDs). As part of the 2030 Agenda for Sustainable Development, member states have set an ambitious target to reduce premature mortality from NCDs - including diabetes - by one third; achieve universal health coverage; and provide access to affordable essential medicines - all by 2030 .

Globally, the number of people with diabetes rose from 108 million in 1980 to 422 million in 2014. The global prevalence of diabetes among adults over 18 years of age rose from $4.7 \%$ in 1980 to $8.5 \%$ in 2014 . Between 2000 and 2016 , there was a $5 \%$ increase in premature mortality from diabetes, with an estimated 1.6 million deaths. ${ }^{2}$

Around $80 \%$ of the world's diabetic population resides in developing countries. Currently, India is contemplated as the diabetes capital of world and there are approximately 72.9 million people suffering from diabetes in India. ${ }^{3}$ As per Indian Diabetic Federation (IDF) data for the year 2013, there were 65.1 million people with diabetes in India, which is predicted to rise up tol09 million by the year $2035 .{ }^{4}$

The prevalence of diabetes is highest in older adults, a population that is increasing due to extended human life span. The elderly population with diabetes are more at risk of developing hypoglycaemia than the adult population because of high co-morbidities, polypharmacy, cognitive impairment and the use of agents that interfere with glucose metabolism. ${ }^{5,6}$

Basically diabetes is a lifestyle disease, requiring multipronged approach for its management, wherein patient has an important role to play in terms of self-care practices, which can be taught to them by educational programs. ${ }^{7}$ Selfcare is multidimensional and includes healthy diet, regular exercise, blood glucose monitoring, foot care and smoking which have be practiced in order to achieve an optimal glycemic control and avoid possible complications such as heart attack, stroke, leg amputation, neuropathy, nephropathy, and retinopathy. ${ }^{8,9}$ Considering the above background, this study was designed to explore the self-care practices among the elderly type 2 diabetics and to know the factors influencing it.

\section{MATERIALS AND METHODS}

Study design

A community based, cross-sectional study was conducted from June-August 2018 among elderly ( $\geq 60$ years) type 2 diabetics residing in rural area, which is the field practice area of Rural Health Training Centre attached to a tertiary care hospital in Hyderabad, Telangana, India.

\section{Sampling size:}

The sample size was calculated by using the formula $\mathrm{n}=$ $4 \mathrm{pq} / \mathrm{L}^{2}$, the anticipated proportion of self-care practices as $50 \%$, with relative precision of $15 \%$ and $95 \%$ confidence interval. Final sample size was estimated to be 177 .

\section{Sampling procedure:}

Identification of the elderly with type 2 diabetes was done in a systematic random sampling method. Each house was visited and elderly person with diabetes were identified and included in the survey. Consecutive houses were contacted till the required sample size was achieved. Only one person from each family was included in the study and was considered to be representative of the selected family so as to avoid duplication of data and recall bias, covering the entire population. 


\section{Inclusion and exclusion criteria:}

Elderly suffering from type 2 diabetics who were physically and mentally fit, residing in the study area for more than one year and gave consent on a voluntary basis to participate in the study were included. People who denied to consent for participating in the study, history of having additional comorbidities like hypertension, renal diseases etc. and those who could not be contacted after three visits were excluded from taking part in the study.

\section{Data collection:}

Data were collected by interviewing all 177 study participants by conducting house-to-house survey using a pre-designed and pre-tested semi structured proforma, in which, part I included socio-demographic profile like age, gender, occupation, religion and socioeconomic status. Part II comprised of questions relating to details of Summary of Diabetes Self-Care Activities (SDSCA). ${ }^{9,10,11,12}$ SDSCA questionnaire contains items related to five different domains of self-care including diet, exercise, blood glucose monitoring, foot care and smoking. The responses for different items were recorded by interviewer according to number of days in previous week a particular self-care activity of a domain was followed on a scale of 0-7. More number of days reflected the better self-care practices and to allow for comparison in terms of percentages the given selfcare activity was considered good if it was followed on most of days ( $\geq 5$ days) in a week. Number of items in five domains included for calculating scores were diet ( 4 items), exercise (2 items), blood glucose monitoring ( 2 item), foot care ( 2 items) and non-smoking behaviour (1 item). Total number of days recorded as response for each item in a domain/subscale was designated as score itself for diet, exercise, foot care and for blood glucose monitoring and non-smoking behaviour scores were either 0 or 7 , and then total score was obtained by adding all scores divided by total number of items giving equal weightage to each. Finally total scores ranged from 0 to 7 for each patient and scores less than 5 were considered poor self-care practices.

The questionnaire used in the study was translated to vernacular language and validated by the investigators. Data was collected after signing a written informed consent form on voluntary basis and assuring the confidentiality face to face interview was conducted. Data analysis was done using SPSS software version 22.0. Descriptive statistics and frequencies were calculated. Study was conducted after taking Institutional Ethical Committee approval.

\section{RESULTS}

A total of 177 elderly diabetics participated in the study. The socio-demographic characteristics of the study participants are shown in Table.1, where majority of $49.71 \%$ were in the age group of $69-70 y e a r s . A$ maximum of $58.76 \%$ were females, $40.11 \%$ were literates, and $55.93 \%$ resided in joint families. A majority of $47.46 \%$ belonged to upper middle and middle class of socioeconomic status [(SES), Modified B. G. Prasad's Classification 2019-India] ${ }^{13}$

\section{TABLES}

Table 1. Sociodemographic profile of the Study Participants $(n=177)$.

\begin{tabular}{|l|c|c|}
\hline \multicolumn{1}{|c|}{ Variables } & Number & Percentage (\%) \\
\hline Age (In Years) & 51 & 28.81 \\
\hline $60-69$ & 88 & 49.71 \\
\hline $70-79$ & 38 & 21.48 \\
\hline$\geq 80$ & 73 & 41.24 \\
\hline Gender & 104 & 58.76 \\
\hline Males & \\
\hline Females & 118 & 66.67 \\
\hline Religion & 48 & 27.12 \\
\hline Hindu
\end{tabular}

\begin{tabular}{|c|c|c|}
\hline Others (Christian, Sikh) & 11 & 6.21 \\
\hline \multicolumn{3}{|l|}{ Education } \\
\hline Literates & 71 & 40.11 \\
\hline Illiterates & 106 & 59.89 \\
\hline \multicolumn{3}{|l|}{ Occupation } \\
\hline Working & 94 & 53.11 \\
\hline Not working & 83 & 46.89 \\
\hline \multicolumn{3}{|l|}{ Type of Family } \\
\hline Nuclear & 32 & 18.07 \\
\hline Joint & 99 & 55.93 \\
\hline Three Generation & 46 & 26.00 \\
\hline \multicolumn{3}{|l|}{ Socioeconomic status* } \\
\hline Upper class & 11 & 6.21 \\
\hline Upper middle class & 23 & 13.00 \\
\hline Middle class & 61 & 34.46 \\
\hline Lower middle class & 59 & 33.33 \\
\hline Lower class & 23 & 13.00 \\
\hline
\end{tabular}

\section{*As per Modified B G Prasad Classification 2019. ${ }^{13}$}

Table 2. Details of Summary Diabetes Self-Care Activities questionnaire (SDSCA) $(\mathrm{n}=177)$

\begin{tabular}{|c|c|c|}
\hline $\begin{array}{l}\text { Summary Diabetes Self-Care } \\
\text { Activities questionnaire (SDSCA) } \\
(\mathrm{n}=177)\end{array}$ & Number & $\begin{array}{c}\text { Percentage } \\
(\%)\end{array}$ \\
\hline \multicolumn{3}{|l|}{ Diet } \\
\hline $\begin{array}{l}\text { Followed specific healthful eating } \\
\text { plan in last seven days }\end{array}$ & 52 & 29.38 \\
\hline $\begin{array}{l}\text { Consumed five or more servings of } \\
\text { fruits and vegetables in last seven } \\
\text { days }\end{array}$ & 114 & 64.41 \\
\hline $\begin{array}{l}\text { Avoided high calorie foods (such as } \\
\text { red meat/full-fat dairy products) in } \\
\text { last seven days. }\end{array}$ & 71 & 40.11 \\
\hline \multicolumn{3}{|l|}{ Exercise } \\
\hline $\begin{array}{l}\text { Participated in at least } 30 \text { minutes of } \\
\text { physical activity (Total minutes of } \\
\text { continuous activity, including } \\
\text { walking) in last seven days. } \\
\end{array}$ & 129 & 72.88 \\
\hline $\begin{array}{l}\text { Participated in a specific exercise } \\
\text { session (such as swimming, walking, } \\
\text { biking) other than what you do } \\
\text { around the house or as part of your } \\
\text { work in last seven days. } \\
\end{array}$ & 55 & 31.07 \\
\hline \multicolumn{3}{|l|}{ Blood Sugar Testing } \\
\hline $\begin{array}{l}\text { Tested your blood sugar in the last } \\
\text { seven days }\end{array}$ & 21 & 11.86 \\
\hline $\begin{array}{l}\text { Tested blood glucose as per the } \\
\text { number of times recommended by } \\
\text { health care provider }\end{array}$ & 69 & 38.98 \\
\hline \multicolumn{3}{|l|}{ Foot care } \\
\hline Examined feet in last seven days & 17 & 9.60 \\
\hline $\begin{array}{l}\text { Inspected the inside of your shoes in } \\
\text { last seven days }\end{array}$ & 12 & 6.78 \\
\hline \multicolumn{3}{|l|}{ Smoking } \\
\hline $\begin{array}{l}\text { Smoked a cigarette-even one Puff } \\
\text { during the past seven days }\end{array}$ & 73 & 41.24 \\
\hline
\end{tabular}

*Summary Diabetes Self-Care Activities questionnaire $(\mathrm{SDSCA})^{9}$

Table 2 depicts the details of SDSCA. ${ }^{9}$ Diet, Exercise, Blood Sugar Testing, Foot care and Smoking were the five domains studied. In the diet domain, $64.41 \%$ consumed five or more servings of fruits and vegetables in last seven days which was mainly vegetables in the routine diet. A maximum of $72.88 \%$ participated in at least 30 minutes of physical activity (Total minutes of continuous activity, including walking) in last seven days, mainly household activities. The least practiced domain was self-care about feet $(<10 \%)$. 
The self-care practices were computed based on Summary Diabetes Self-Care Activities questionnaire (SDSCA). $27.12 \%$ and a majority of $72.88 \% \%$ had good and poor self-care practices respectively. Association of parameters of the Study Participants and SDSCA is illustrated in Table 3.

Table 3: Association of parameters of the Study Participants and SDSCA

\begin{tabular}{|c|c|c|c|c|c|}
\hline \multirow[t]{3}{*}{ Variables } & \multicolumn{5}{|c|}{ SDSCA } \\
\hline & \multicolumn{2}{|c|}{ Good Self-care (n=48, 27.12\%) } & \multicolumn{2}{|c|}{ Poor Self-care $(n=129,72.88 \%)$} & \multirow[t]{2}{*}{ Significance } \\
\hline & Number & Percentage & Number & Percentage & \\
\hline \multicolumn{5}{|l|}{ Age (In Years) } & \multirow{4}{*}{$\begin{array}{c}\chi^{2}=46.271 \mathrm{l} \\
\mathrm{p}=0.00001 \mathrm{df}=2 \text { Significant }\end{array}$} \\
\hline $60-69(51)$ & 32 & 62.75 & 19 & 37.25 & \\
\hline $70-79(88)$ & 10 & 11.36 & 78 & 88.64 & \\
\hline$\geq 80(38)$ & 06 & 15.79 & 32 & 84.21 & \\
\hline \multicolumn{6}{|l|}{ Gender } \\
\hline Males (73) & 26 & 35.61 & 47 & 64.39 & \multirow{2}{*}{$\begin{array}{c}\chi^{2}=4.5393 \\
\mathrm{p}=0.033125 \mathrm{df}=1 \text { Significant }\end{array}$} \\
\hline Females (104) & 22 & 21.15 & 82 & 78.85 & \\
\hline \multicolumn{6}{|l|}{ Education } \\
\hline Literates (71) & 39 & 54.93 & 32 & 45.07 & \multirow{2}{*}{$\begin{array}{c}\chi^{2}=46.3951 \\
\mathrm{p}<0.0001 \mathrm{df}=1 \text { Significant }\end{array}$} \\
\hline Illiterates (106) & 09 & 8.49 & 97 & 91.51 & \\
\hline \multicolumn{6}{|l|}{ Type of Family } \\
\hline Nuclear (32) & 10 & 31.25 & 22 & 68.75 & \multirow{3}{*}{$\begin{array}{c}\chi^{2}=2.986 \\
p=0.2246 \mathrm{df}=2 \text { Not Significant }\end{array}$} \\
\hline Joint (99) & 30 & 30.30 & 69 & 69.70 & \\
\hline Three Generation (46) & 8 & 17.39 & 38 & 82.61 & \\
\hline \multicolumn{6}{|l|}{ Socioeconomic Status* } \\
\hline I (11) & 4 & 36.36 & 7 & 63.64 & \multirow{3}{*}{$\begin{array}{c}\chi^{2}=0.516 \\
p=0.7727 \mathrm{df}=2 \text { Not Significant }\end{array}$} \\
\hline II+III (84) & 22 & 26.19 & 62 & 73.81 & \\
\hline IV+V (82) & 22 & 26.19 & 60 & 73.81 & \\
\hline \multicolumn{6}{|c|}{ Family history of Diabetes } \\
\hline Yes (56) & 12 & 21.43 & 44 & 78.57 & \multirow{2}{*}{$\begin{array}{c}\chi^{2}=1.3419 \\
p=0.246695 \mathrm{df}=1 \text { Not Significant }\end{array}$} \\
\hline No (121) & 36 & 29.75 & 85 & 70.25 & \\
\hline \multicolumn{6}{|l|}{ Duration of Diabetes } \\
\hline 1-5years (59) & 39 & 66.10 & 20 & 33.90 & \multirow{2}{*}{$\begin{array}{c}\chi^{2}=68.0472 \\
p=0.00001 \mathrm{df}=1 \text { Significant }\end{array}$} \\
\hline$>$ 5years $(118)$ & 09 & 7.62 & 109 & 92.38 & \\
\hline
\end{tabular}

*As per modified BG Prasad Classification-2019 ${ }^{13}$

Good self-care activities were seen in study participants aged 60-69 years of age; younger age group had better practices which was statistically significant. $(\chi 2=46.2711, \mathrm{p}=0.00001) \mathrm{A}$ majority of $35.61 \%$ males and $21.15 \%$ females had a good self-care practice which was statistically significant $(\chi 2=4.5393, p=0.033125)$. Literates had good self-care practices in comparison to illiterates. $(\chi 2=46.3951, \mathrm{p}<0.0001)$. $66.10 \%$ of the study participants who had diabetes duration of 1-5years had better self-care practices which was statistically significant $(\chi 2=68.0472, p=0.0 .00001)$. Other factors influencing the self-care practices were nuclear family and class I socioeconomic status (As per Modified BG Prasad Classification 2019) ${ }^{13}$

\section{DISCUSSION}

This study was done to assess the prevalence of good diabetes self-care behaviour in an urban south Indian community. The present study sheds new light on the avenues of self-care of elderly diabetics and factors influencing it among rural population. The study recognized many factors that impacted significantly on self-care practices of elderly diabetics.

In the present study, it was found that $72.88 \%$ of elderly diabetics had poor self-care practices.

A study done by V. Gopichandra et al., ${ }^{14}$ department of Community Health, Christian Medical College, Vellore, India in 2012 showed that $20.5 \%$ belonged to $61-70$ yearsand $59 \%$ females whereas in the present study $49.71 \%$ belonged to $70-$ 79 years of age group and $58.76 \%$ were females.

In the present study $40.11 \%$ were literates and which was in contrast to a study done by Rajasekharan D et al., ${ }^{4}$ in Mangalore, Karnataka in 2015 wherein $80 \%$ of the study participants were literates. This can be reason for high poor self care practice in our study.
In a study done by Goyal $\mathrm{N}$ et $a l .,{ }^{3}$ in Moradabad, UP, India in 2019 found that $43.45 \%$ respondents have poor self-care practices, $50 \%$ diabetic patients in present study followed specific healthful eating plan, $47.6 \%$ consumption of five or more servings of fruits and vegetables, $52.3 \%$ responded that they had participated in at least 30 minutes of continuous physical activity on most days of past week, 14.2\%) inspected their footwear on most days of past week, $80.9 \%$ had not smoked during the past seven days of week whereas in the present study $72.88 \%$ of elderly diabetics had poor self-care practices in the present study, 29.38 followed specific healthful eating plan in last seven days.

In the present study 64.41 consumed five or more servings of fruits and vegetables in last seven days, which were mainly vegetables because as the study area was rural population vegetables were grown in own lands and consumed frequently. Only $31.07 \%$ study participants did specific exercise session which was on a lesser note because as they were from rural sector routine agriculture work was considered as exercise to them. $38.98 \%$ tested blood glucose as per the number of times recommended by health care provider, because as many of them considered blood glucose testing mandatory only if complications occurred. Caring of the foot was the least $(<10 \%)$ self-care practices, using foot ware was also on lesser note, which shows that many of our study participants were not aware of the multi organ and micro vascular complications of diabetes. $41.24 \%$ of the study participants continued smoking habits even though they were advised to quit the habits. Many of the study participants did not know about the hypoglycaemic symptoms and none of the study participants had health card with details of disease treating doctor and emergency contact number.

\section{CONCLUSION}

Self-care activities practiced rightly and routinely among diabetics can have a dramatic impact in maintaining the 
health.If diabetes goes uncontrolled, it creates consequences for health and well-being which has an effect on finances of individuals and their families, and the economy of nation. From the present study analysis it is clear that, self-care activities are poor among elderly diabetics, stronger responses from the government, civil society and people with diabetes themselves must all act together in combating the complications of diabetes and participate in Self care training sessions, and thereby reduce the morbidity and mortality and thus help in healthy ageing of the population.

\section{ACKNOWLEDGMENT}

We express our sincere gratitude to all the elderly who participated in the study and spent their precious and valuable time.

\section{SOURCE OF FUNDING}

None

\section{CONFLICT OF INTEREST}

Nil

\section{REFERENCES}

1. Global report on diabetes. World Health Organization 2016 [Accessed on 9 November 2020] Available at: https://www.who.int/ publications/i/item/ 9789241565257 .

2. World Health Organization. Diabetes. [Accessed on 9 November 2020] Available at: https://www.who.int/news-room/fact-sheets/detail/diabetes\# : : text=Key\%20facts,in\%20premature $\% 20$ mortality $\% 20$ from $\% 20$ diabetes.

3. Goyal N, Gupta SK. Self-care practices among known type 2 diabetic patients in Haldwani, India: a community based cross-sectional study. Int J Community Med Public Health 2019;6:1740-6.

4. D Rajasekharan et al., Self-Care Activities Among Patients with Diabetes Attending a TertiaryCare Hospital in Mangalore Karnataka, India. Ann Med Health Sci Res 2015;(1)59-64.

5. Ahmad Sharoni SK et al., Social support and self-care activities among the elderly patients with diabetes in Kelantan. Malaysian Family Physician 2015;(10) 1:34-43.

6. Katie Weinger et al., Diabetes Self-Care and the Older Adult. West J Nurs Res. 2014;36(9): 1272-1298.

7. Dinesh PV, Kulkarni AG, Gangadhar NK.Knowledge and self-care practices regarding diabetes among patientswith Type 2 diabetes in Rural Sullia, Karnataka: A community-based, cross-sectional study. J Family Med Prim Care 2016;5:847-52.

8. Raithatha SJ, Shankar SU, Dinesh K. Self-Care Practices among Diabetic Patients in Anand District of Gujarat. ISRN Family Med 2014:743791.

9. DEBORAH J. TOOBERT et al., The Summary of Diabetes Self-Care Activities Measure.Diabetes Care 2000;23(7):943-950.

10. Mohandas A, Bhasin SK, Upadhyay M, Madhu SV. Diabetes self care activities among adults 20 years and above residing in a resettlement colony in East Delhi.Indian J Public Health 2018;62:104-10.

11. Kushwaha AS, Kumari S, Kushwaha N. Self care in diabetes: a study amongst diabetics in an urban community. Int J Community Med Public Health. 2016;3:293-8.

12. Chandrika K, Das BN, Syed S, Challa S. Diabetes self-care activities: A community-based survey in an urban slum inHyderabad, India. Indian J Community Med 2020;45:307-10.

13. Mahmood S. Prasad's Socioeconomic Scale Updated For 2019. National Journal of Community Medicine. 2019;10(6):388.

14. Gopichandran V, Lyndon S, Angel MK, Manayalil BP, Blessy KR, Alex RG, Kumaran V, Balraj V. Diabetes self-care activities: a community-based survey in urban southern India.Natl Med J India. 2012 Jan-Feb;25(1):14-7. 